\title{
CONTRIBUCIONES AL DEBATE JURÍDICO DEL TRABAJO SEXUAL EN COLOMBIA
}

\author{
Misael Tirado Acero \\ Universidad Católica de Colombia
}

\begin{abstract}
Resumen
En el marco del concepto de un Estado social de Derecho, la prostitución es el reflejo de relaciones sociales controversiales y discriminatorias presentes en la historia de nuestro país. Tras la ambivalencia en materia de protección social en la regulación o reglamentación de esta realidad social, la Sentencia T-629 de 2010 ofrece un marco de discusión sobre la dignidad humana, la libertad, el derecho al trabajo y a un régimen prestacional legítimo. En la actualidad cursa el Proyecto de Ley 079 de 2013, con el que se intenta dar cumplimiento a los mandatos de la Corte Constitucional, con el objetivo de garantizar la dignidad de las personas que ejercen la prostitución no forzada.
\end{abstract}

Palabras clave: derechos, Derecho Laboral, discriminación, prostitución.

El autor: sociólogo con posgrados en Economía y Evaluación Social de Proyectos, doctor en Sociología Jurídica e Instituciones Políticas y posdoctor en Derecho. Profesor visitante del Doctorado Intensivo Internacional de la Facultad de Derecho de la Universidad de Buenos Aires y de otras universidades en Chile, Brasil, Perú, Panamá, México y Estados Unidos; docente investigador de la Universidad Católica de Colombia; docente investigador de Sociología Jurídica y Metodologías de la Investigación en pregrado y posgrado en las Facultades de Derecho de la Universidad Nacional de Colombia, de la Universidad Externado de Colombia y de la Universidad Gran Colombia; investigador social desde la perspectiva de juventudes, género, poblaciones en alto riesgo y comunidades urbanas y rurales en situación de conflicto, tanto en atención como en prevención en el tema de derechos humanos y políticas públicas; director de la Fundación FEFSA para la Formulación y Evaluación de Proyectos y consultor de la Presidencia de la República y de Naciones Unidas. Dirección postal: carrera 10 No. 96-79. Correo electrónico: misaeltirado@gmail.com; misaeltirado@fundacionfefsa.org

Recibido: 3 de marzo de 2014; evaluado: 15 de abril de 2014; aceptado: 27 de mayo de 2014. 


\title{
CONTRIBUTIONS TO THE LEGAL DEBATE ON SEX WORK IN COLOMBIA
}

\author{
Misael Tirado Acero \\ Universidad Católica de Colombia
}

\begin{abstract}
Prostitution, in the framework of a Democratic and Social State of Rule of Law, embody a set of controversial and discriminatory social relations that have been present all along the history of our country. After the ambivalence in the matter of social protection in the regulation or regimentation of this social reality, the Ruling T-629 of 2010 offers a framework of discussion, especially on human dignity, freedom, the right to work and a legitimate system of benefits. Nowadays, the Bill 079 of 2013 is being carried out, which tries to comply the writs of the Constitutional Court with the purpose to guarantee the dignity of the people who exercise prostitution by their own will.
\end{abstract}

Keywords: Rights, Lanour Rights, discrimination, prostitution.

About the author: Sociologist with postgraduate studies in Economy and Social Evaluation of Projects, Doctor in Sociology of Law and Political Institutions and postdoctoral scholar in Law. Visiting Professor of the Intensive International Doctorate in Law at the Law Faculty of Universidad de Buenos Aires and other universities in Chile, Brazil, Peru, Panama, Mexico and the United States; Research Professor at Universidad Católica de Colombia; Research Professor of Sociology in Law and Research Methodologies for bachelor and postgraduate degrees at the Law Faculties from Universidad Nacional de Colombia, Universidad Externado de Colombia and Universidad Gran Colombia. Social researcher from the perspective of youth studies, gender and vulnerable population, including urban and rural communities in situations of conflict. He has worked on Human Rights and Public Policy in the area of attention as well as in prevention. Director of the FEFSA Foundation for the Formulation and Evaluation of Projects. Advisor for the Presidency of the Republic and the United Nations. Address: Carrera 10 No.96-79. E-mail: misaeltirado@gmail.com; misaeltirado@fundacionfefsa.org

Received: March 3, 2014; reviewed: April 15, 204; accepted: May 27, 2014. 


\section{Introducción}

En el contexto de las múltiples ofertas del comercio sexual, la prestación remunerada de servicios sexuales resulta siempre un tema atractivo que implica la existencia de personas excluidas en un mundo oculto, extraño, ajeno, inseguro y cargado de imágenes enrarecidas por los sucesos de las calles, transitadas con rapidez ante el ojo de la buena moral y con lentitud para el deseo sexual ávido de un servicio.

La prostitución es un fenómeno social mucho más abarcador y complejo que una realidad que ha existido siempre. Es mucho más que "el oficio más antiguo del mundo". Tiene más que ver con las formas de relacionarnos con los demás, con la experiencia de la sexualidad y del deseo, con las ideas de dominación y con una ilusión del acceso al cuerpo de la otredad. La prostitución no es una actividad aislada, pues se enmarca en estructuras culturales y dinámicas económicas, políticas e ideológicas de una sociedad determinada.

Es de amplio conocimiento que la mayoría de oferentes de estos servicios es mujer. Esto no es solo un dato vacío, sino que supone que su lado contrario, es decir, la demanda, esta movida por hombres que buscan servicios sexuales con mujeres "adultas" en el marco de una sociedad machista, heterosexual.

Si es notorio que la prostitución es ejercida en especial por mujeres y demandada por hombres, ¿por qué en el imaginario social fluyen imágenes de mujeres semidesnudas a la espera de clientes? ¿En dónde está el cliente en esta caricatura de la vida social? Resulta que el cliente no aparece, no registra ni está en las bases de datos oficiales; es un fantasma, un protagonista anónimo, sin cara, sin nombre, sin perfil y desclasificado.

El hecho de que el cliente sea un fantasma y las mujeres que prestan servicios sexuales sean una imagen de mala conducta y pocos valores refleja una asimetría constitutiva de nuestras sociedades. Si bien existe prostitución masculina, no se puede desconocer que la carga peyorativa que trae el comercio sexual es asumida por las mujeres oferentes de esta práctica.

La negación histórica de los derechos fundamentales a una o de una población —en este caso, quien se dedica a la prostitución — ${ }^{1}$ tiene su origen en múltiples

\footnotetext{
La palabra viene del latín prostituio: exhibir para la venta. Las denominaciones prostitución, trabajo sexual y explotación sexual tienen connotaciones distintas: la primera está sujeta a una necesidad, bien sea de tipo económico, lúdico o intelectual en la que se intercambia sexo por una remuneración; la segunda implica un valor agregado y el ofertante sexual o erótico ve su actividad como una labor o un trabajo más; por lo
} 
causas, pero parece haber suficiente evidencia para considerar que el sector femenino oferente de servicios sexuales ha sido quien ha cargado con el estigma y con diversas formas de violencia cuya tipificación respecto a los delitos sexuales ${ }^{2}$ se encuentra en la Ley 599 de 2000 (Código Penal) y la Ley 906 del 2004 (Código de Procedimiento Penal).

Por otra parte, si bien la prostitución es muy antigua, también es novedosa, creativa y responde a las necesidades de una oferta diversificada día tras día. Tiene movimientos migratorios — muchos de ellos ilegales y constituyen delito—, tiene dinámicas que pueden vulnerar la integridad de quien la ejerce, así como involucrar a sectores indefensos como a niños, niñas y adolescentes; por tanto, es deber de los Estados propiciar la defensa, la protección, la promoción y el amparo, entre otros, de forma priorizada y reforzada de este grupo poblacional.

Considerar a la prostitución como una simple transacción es desconocer una multiplicidad de fenómenos que se despliegan por medio de las manifestaciones de la sexualidad, que implican una serie de dinámicas en las que se pone en juego la protección de la integridad, la libertad, la formación sexual, la dignidad y la autonomía como derechos fundamentales.

contrario, la explotación sexual tiene que ver con el usufructo de la sexualidad y eroticidad de otra persona por parte de un tercero. Misael Tirado, Comercio sexual: una mirada desde la sociología jurídica (Lima: Instituto Internacional de Derecho y Sociedad, 2010), 23; Misael Tirado, Comercio sexual (Bogotá: Instituto Latinoamericano de Altos Estudios, 2013), 12.

2 "Artículo 188. El que promueva, induzca, constriña, facilite, colabore o de cualquier otra forma participe en la entrada o salida de personas del país sin el cumplimiento de los requisitos legales, incurrirá en prisión de seis (6) años a ocho (8) años y multa de cincuenta a cien salarios mínimos legales mensuales [...].

Artículo 188A. Trata de personas. El que capte, traslade, acoja o reciba a una persona, dentro del territorio nacional o hacia el exterior, con fines de explotación, incurrirá en prisión de trece (13) a veintitrés (23) años y una multa de ochocientos (800) a mil quinientos (1.500) salarios mínimos legales mensuales vigentes [...]. Artículo 188 B. Circunstancias de agravación punitiva. Las penas para los delitos descritos en el Artículo 188 y 188 A, se aumentarán de una tercera parte a la mitad, cuando:

1. Cuando se realice en persona que padezca inmadurez psicológica, trastorno mental, enajenación mental y trastorno psíquico, temporal o permanentemente o sea menor de 18 años.

2. Como consecuencia, la víctima resulte afectada en daño físico permanente y/o lesión psíquica, inmadurez mental, trastorno mental en forma temporal o permanente o daño en la salud de forma permanente.

3. El responsable sea cónyuge o compañero permanente o pariente hasta el tercer grado de consanguinidad, segundo de afinidad y primero civil.

4. El autor o partícipe sea servidor público [...].

Artículo 213. El que con ánimo de lucrarse o para satisfacer los deseos de otro, induzca al comercio carnal o a la prostitución a otra persona, incurrirá en prisión de dos (2) a cuatro (4) años [...].

Artículo 214. El que con ánimo de lucrarse o para satisfacer los deseos de otro, constriña a cualquier persona al comercio carnal o a la prostitución, incurrirá en prisión de cinco (5) a nueve (9) años y multa de cincuenta (50) a quinientos (500) salarios mínimos legales mensuales vigentes. Colombia, Congreso de la República. Ley 599 de 2000, "Por la cual se expide el Código Penal" (Bogotá: Diario Oficial No. 44.097, 24 de julio de 2000). 
De la complejidad propia de la prostitución surge la imperiosa necesidad de actuar desde diferentes ángulos, como el ordenamiento jurídico, para contrarrestar los efectos negativos de una actividad que ha puesto en vilo derechos de una población que poco ha contado, que poco ha sido escuchada, aunque muchos hayan tomado sus servicios.

\section{Recorrido jurídico del trabajo sexual contemporáneo en Colombia}

Las perspectivas desde las que se ha abordado la prostitución en el marco jurídico han sido dos: el prohibicionismo y la reglamentación. Tales corrientes plantean dos polos en la discusión respecto a la forma en la que el Estado debe concebir el fenómeno, pues, a fin de cuentas, es en el Estado donde se concentra una noción de comunidad o, como lo llamaría Anderson, ${ }^{3}$ la comunidad imaginada, lugar en el que se condensan las ideas generalizadas acerca de lo deseable en una sociedad.

El prohibicionismo se fundamenta en que el comercio sexual atenta contra los derechos humanos de las personas que trabajan en él, ya que va en contra de la dignidad humana y restringe la libertad sexual. Desde este modelo se considera que:

[...] se deben tomar acciones legales contra las personas que se encuentran dentro de él; desde este punto de vista, el modelo se instaura dentro de un planteamiento de corte conservador, cuyo principal discurso es la moral, que va acompañado de ideologías politizadas en cuanto a filiaciones de tipo religioso o de clase. ${ }^{4}$

En el polo opuesto están quienes consideran que el comercio sexual debe ser reglamentado y que las personas que trabajan en prostitución deben ser reconocidas como trabajadoras del sexo. En términos legales, implica un reconocimiento de su ejercicio y, en términos prácticos, involucra un marco jurídico que impulsa el mejoramiento de las condiciones en las que se prestan los servicios sexuales. Además, se hace un seguimiento con el fin de evitar delitos como la explotación sexual de

Benedict Anderson, Comunidades imaginadas: reflexiones sobre el origen y la difusión del nacionalismo (México D. F.: Fondo de Cultura Económica, 1993), 56.

$4 \quad$ Tirado, Comercio sexual, 306. 
personas con mayoría de edad, la Explotación Sexual Comercial de Niños, Niñas y Adolescentes (ESCNNA) y la trata de personas con fines de explotación sexual. ${ }^{6}$

En Colombia no se ha presentado un marco jurídico que considere la prostitución como un delito; sin embargo, sí han existido visiones que, desde la reglamentación, han concebido el fenómeno desde diversas perspectivas.

Para comienzos de la década del setenta, el Decreto 1335 (Código Nacional de Policía), modificado por el Decreto 522 de 1971, en el Capítulo VIII, Artículo 178, definió a quien ejerce la prostitución como "la persona que trafica habitualmente con su cuerpo, para satisfacción erótica de otras varias, con el fin de asegurar, completar o mejorar la propia subsistencia o la de otro". Más adelante señaló que es función del Estado "utilizar los medios de protección social a su alcance para prevenir la prostitución y para facilitar la rehabilitación de la persona prostituida". Si bien existe un reconocimiento de la actividad, se puede alcanzar a detallar la percepción de la prostitución como un mal, una situación o enfermedad social de la cual las personas deben rehabilitarse.

En 1995, la Corte Constitucional7 sostiene que "para el Estado social de Derecho la prostitución no es deseable, por ser contrario a la dignidad de la persona humana el comerciar con el propio ser". ${ }^{8}$ Por tal motivo, a pesar de que se reconoce como una actividad que inexorablemente se lleva a cabo, es considerada como un mal menor que es preferible tolerar y controlar, ya que, en caso contrario, puede que "se esparza clandestina e indiscriminadamente en la sociedad, dañando sobre todo a la niñez y a la juventud".

Resulta interesante que en esta Sentencia se considere a quien ejerce la prostitución como una persona que está por fuera del ordenamiento moral de la sociedad, sin sopesar el jurídico y se estigmatizan como los y las parias, las y los enfermos de la sociedad que requieren tratamiento y tolerancia.

5 La mal denominada prostitución infantil o de menores de edad hoy en día se asume como explotación sexual comercial, en la que no cabe el autoagenciamiento, la voluntariedad o el consentimiento de NNA.

6 República de Colombia, Constitución Política (Bogotá: Legis, 2002), art. 215. Este Artículo fue derogado por la Ley 747 de 2002, Artículo 4.

7 Señala pautas para la implementación de zonas de alto impacto para el ejercicio de la prostitución y reglamenta el uso del suelo en cumplimiento del Plan de Ordenamiento Territorial de Bogotá, por medio de las disposiciones contenidas en los Decretos distritales 619 de 2000, 469 de 2003 y 10 de 2004.

8 Colombia, Corte Constitucional, Sentencia T-620 de 14 de diciembre de 1995, M. P. Vladimiro Naranjo Mesa. 
En alusión a Obregón, ${ }^{9}$ el discurso jurídico tiene mucho que ver con los discursos médico-científicos que catalogaron como enferma a la persona que decidiera prestar su cuerpo con fines sexuales, visión establecida en el país desde el siglo XIX y que es evidente en la Sentencia T-620 de 1995, en donde se expresa que:

[...] si se trata por varios medios de evitar que la mujer se prostituya, el Estado tienda a alejar ese mal ejemplo de las zonas residenciales, para evitar, entre otras, que la niñez y la juventud se vean impelidas hacia tan lamentable oficio.

Cabe resaltar que para este momento histórico aún no se reconoce la prostitución como un trabajo y que, además, se dejan de lado a los hombres que ejercen este oficio.

En el año 2010 se emitió la Sentencia T-629, ${ }^{10}$ que quizás es la más profunda relacionada con la prostitución. En términos del senador Benedetti, en la exposición de motivos del Proyecto de Ley 079 de 2013, esta Sentencia "es seguramente la sentencia más completa y enriquecedora constitucionalmente hablando, providencia que mostró con altura la función liberal, republicana y garantista del Alto Tribunal Constitucional".

La Sentencia T-629 de 2010 surgió de una acción de tutela en la que una mujer demandó sus derechos al ser despedida (en estado de embarazo) de un lugar en el que se ejerce prostitución. La situación resulta jurídicamente compleja, si se tienen en cuenta los antecedentes constitucionales. En este caso, se deben tutelar los derechos de una mujer despedida en estado de embarazo y se tiene que definir el estatus jurídico y laboral de la prostitución como actividad.

Como premisa frente al contrato de trabajo y a la protección de la mujer cabeza de familia y en estado de embarazo, la Corte Constitucional afirmó en la Sentencia que es deber del Estado:

Reforzar sus derechos laborales respecto de los demás trabajadores, en el sentido de limitar al empleador su poder de disponibilidad de la trabajadora e

\footnotetext{
Diana Obregón, "Médicos, prostitución y enfermedades venéreas en Colombia (1886-1951)", História, Ciências, Saúde-Manguinhos 9, supl. (2002): 36, www.scielo.br/pdf/hcsm/v9s0/07.pdf (acceso noviembre 20, 2013).

10 Equipara la prostitución al trabajo sexual e insta a las instituciones parte a implementar medidas para salvaguardar y proteger a las personas que se encuentran en esa situación. Colombia, Corte Constitucional, Sentencia T-629 de 13 de agosto de 2010, M. P. Juan Carlos Henao Pérez.
} 
incrementar pari passu la estabilidad en el empleo de ésta como forma de protección efectiva de los bienes constitucionales relacionados con ella: derechos de la mujer, derecho a la no discriminación, derechos de los niños, derechos de la familia. Por esto también, la estabilidad laboral reforzada predicable de la mujer en estado de embarazo o lactancia y de la que es madre cabeza de familia, se puede entender como un avance más en el proyecto constitucional de ser un Estado garante de la libertad, la igualdad y la dignidad humanas y de que se haga efectivo el trabajo como principio, derecho, deber y libertad, como forma de participar de las oportunidades que ofrece el desarrollo, en ejercicio de sus capacidades y condiciones especiales. ${ }^{11}$

La protección de los derechos de la mujer cabeza de familia, en estado de embarazo y que labora como trabajadora sexual permite identificar una situación de vulneración de derechos en los que la Corte decide que:

Habrá contrato de trabajo y así debe ser entendido, cuando el o la trabajadora sexual ha actuado bajo plena capacidad y voluntad, cuando no hay inducción ninguna a la prostitución, cuando las prestaciones sexuales y demás del servicio, se desarrollen bajo condiciones de dignidad y libertad para el trabajador y por supuesto cuando exista subordinación limitada por el carácter de la prestación, continuidad y pago de una remuneración previamente definida. ${ }^{12}$

Con estos antecedentes y desde la perspectiva que otorga el estatus de trabajo a la prostitución, en adelante el ejercicio de la prostitución será denominado trabajo sexual. Frente al tipo de contrato, la Sentencia sostiene que se puede presentar la modalidad de contrato realidad, el cual implica una serie de obligaciones tanto para el trabajador como para el empleador. No obstante, debido al carácter del trabajo, que en muchos aspectos puede poner en entredicho la dignidad de la persona que lo ejerce, si bien existe una subordinación precaria, también se reconoce la existencia de una precariedad frente a la estabilidad laboral y al derecho a ser restituido en caso de despido injustificado.

\section{Derechos humanos en el caso de la Sentencia T-629 de 2010}

Si retomamos la idea de los derechos fundamentales como base para una ética —si se quiere, universal — es relevante remitirnos al principio fundamental de la libertad y la dignidad humana.

Colombia, Corte Constitucional, Sentencia T-629.

12 Colombia, Corte Constitucional, Sentencia T-629. 
Con base en este principio, la Sentencia T-629 partió de la revisión de la jurisprudencia sobre la igualdad en la Constitución como eje de derechos, para definir la existencia de fundamentos jurídicos y, en consecuencia, considerar un trato desigual en materia de derechos laborales, con lo cual se sustentó la licitud de la prostitución.

La tutela de la mujer que reclamó por sus derechos dejó al descubierto estas nuevas formas de organización y reivindicación de los actores sociales, que asimilan la universalidad de su protesta como fuente necesaria para la reivindicación de sus derechos, en especial de su libertad.

En el caso de las personas que ejercen el trabajo sexual, se han sumado múltiples asociaciones de mujeres a lo largo del mundo, primordialmente a favor de los derechos de esta población, que luchan por la reivindicación del trabajo, siendo dirigidas todas las reclamaciones al Estado por ser el protagonista que garantiza su cumplimiento, así mismo como de la comunidad internacional. ${ }^{13}$

Las nuevas formas de organización y reivindicación se reconocen, a su vez, en los derechos fundamentales promulgados en la Constitución Política de 1991, que invoca:

Son fines esenciales del Estado: servir a la comunidad, promover la prosperidad general y garantizar la efectividad de los principios, derechos y deberes consagrados en la Constitución; facilitar la participación de todos en las decisiones que los afecten y en la vida económica, política, administrativa y cultural de la Nación; defender la independencia nacional, mantener la integridad territorial y asegurar la convivencia pacífica y la vigencia de un orden justo. ${ }^{14}$

Además, acerca de las garantías esenciales para acceder como principio fundamental a la libertad, afirma:

Todas las personas nacen libres e iguales ante la ley, recibirán la misma protección y trato de las autoridades y gozarán de los mismos derechos, libertades y oportunidades sin ninguna discriminación por razones de sexo, raza, origen nacional o familiar, lengua, religión, opinión política o filosófica.

13 Misael Tirado, "El debate entre prostitución y trabajo sexual: una mirada desde lo socio-jurídico y la política pública", Revista de Relaciones Internacionales, Estrategia y Seguridad 6, núm. 1 (2011): 140.

14 República de Colombia, Constitución Política, art. 2. 
El Estado promoverá las condiciones para que la igualdad sea real y efectiva y adoptará medidas en favor de grupos discriminados o marginados.

El Estado protegerá especialmente a aquellas personas que por su condición económica, física o mental, se encuentren en circunstancia de debilidad manifiesta y sancionará los abusos o maltratos que contra ellas se cometan. ${ }^{15}$

De esta forma, la Sentencia busca tutelar los derechos consagrados en la Constitución, con base en la conservación y protección del principio de igualdad ante la ley, la prohibición de la discriminación y la promoción de la igualdad material.

Tanto en la tutela interpuesta que da origen a la Sentencia T-629 de 2010 como en la situación de trabajadores sexuales en general se encuentran realidades en las que ha existido una constante discriminación y nula protección de los derechos laborales ante la ausencia de contrato laboral o de mecanismos que amparen sus derechos, por lo que la Sentencia resulta primordial en la protección de los derechos fundamentales de esta población.

Sumado a lo anterior, los derechos laborales y de libertad no pueden aplicarse en sentido estricto de igualdad, debido a que la prostitución cuenta con una estructura histórica que no permite equiparar o comparar esta actividad económica con cualquier otra. Las mujeres que ejercen este trabajo se han convertido en objeto de estigma, justificado por múltiples discursos que las han hecho víctimas de una sociedad machista, que castiga la independencia y libre decisión de las mujeres que usan sus cuerpos, su eroticidad y en especial sus órganos sexuales y reproductivos con fines comerciales.

En el contexto de una población que arrastra concepciones morales que las victimiza, el concepto de libertad no podría aplicarse en un ámbito de igualdad, por lo que un trato y una conceptualización diferencial es requerido si se quieren proteger, promover y restaurar los derechos lesionados de esta población. Por este motivo, la Corte Constitucional insta a un concepto de libertad que contempla un trato diferencial de acuerdo con criterios de proporcionalidad, que se debe realizar según la evaluación de idoneidad, necesidad y proporcionalidad en sentido estricto.

15 República de Colombia, Constitución Política, art. 13. 
Por otra parte, junto con el derecho a la libertad — derecho fundamental en el que se funda la protección y licitud del trabajo sexual- se reconoce la necesidad de incluir el principio y el derecho a la dignidad, que representa para el Estado colombiano un pilar sobre el que se deben fundamentar otros derechos.

Afirma la Sentencia T-629, con origen en la T-881 de 2002, que el Estado debe garantizar:

(i) la autonomía o posibilidad de diseñar un plan vital y de determinarse según sus características (vivir como se quiere), (ii) ciertas condiciones materiales concretas de existencia (vivir bien), (iii) la intangibilidad de los bienes no patrimoniales, integridad física e integridad moral (vivir sin humillaciones). ${ }^{16}$

En otros términos, la protección de la dignidad humana implica la posibilidad de un posicionamiento social en el que las personas puedan adquirir capitales valiosos socialmente (cultural, social y económico, entre otros). ${ }^{17}$ Además de estimular las competencias que permitan llevar una $\mathrm{u}$ otra forma de vida de acuerdo con la libre elección de las personas, ${ }^{18}$ el Estado debe brindar las herramientas para que, a pesar de las asimetrías constitutivas de la sociedad, las personas puedan plantear un proyecto de vida con las condiciones materiales que lo permitan.

Entonces, desde su perspectiva liberal es función del Estado asegurar a los ciudadanos las garantías y condiciones para que puedan desarrollarse y tener plenas capacidades de elección sobre su propia vida, ya que, como lo plantea Appiah, "el cultivo de la propia individualidad es en sí mismo parte del bienestar, algo bueno in $\mathrm{se}^{\text {". }}{ }^{19}$

Acerca de las condiciones necesarias para el proyecto de vida de quien ejerce la prostitución, es pertinente señalar varios aspectos que deben ser tenidos en cuenta para la discusión: 1. diferencias culturales de género que posicionan a las mujeres en desventaja económica, política y social; 2 . diferencias étnicas que facilitan la subordinación de determinados grupos sociales; 3 . diferencias de clase que posibilitan o no condiciones de marginalidad y necesidad que son aprovechados en contra de los intereses de las trabajadoras y los trabajadores sexuales.

Colombia, Corte Constitucional, Sentencia T-629.

Pierre Bourdieu, Sociología y cultura (México D. F:: Grijalbo, 1984), 21.

Amartya Sen, Desarrollo y libertad (Barcelona: Planeta, 2000), 15.

Kwame Appiah, La ética de la identidad (Buenos Aires: Latingráfica, 2007), 29. 
Un proyecto de vida deseable desde el criterio de la dignidad humana —en el caso de la prostitución, que se desarrolle en condiciones de libre ejercicio y con plena conciencia—debe contemplar múltiples dimensiones como las ya señaladas, por lo que el Estado debe brindar las facilidades y oportunidades para que todas y todos sus ciudadanos lo consigan.

\section{Camino hacia la formalización de los derechos de la población que ejerce prostitución en Colombia}

El año 2010 fue decisivo para la población que ejerce prostitución en el país. En el plano legislativo se venían gestando propuestas que, cada vez con más claridad, intentaban reconocer los derechos de esta población. Organizaciones de la sociedad civil diseñaron proyectos más fuertes y contaron con mayor apoyo, como el caso de la Asociación de Mujeres Buscando Libertad (Asmubuli), la cual forma parte de la creciente organización internacional Redtrasex..$^{20}$

En el plano institucional, ${ }^{21}$ surgió un interés creciente por conocer las dinámicas propias de la prostitución en el país y en el plano legislativo, en la ciudad de Bogotá se tomaron medidas más incluyentes respecto a las personas dedicadas a la prostitución, ${ }^{22}$ sin olvidar esfuerzos en lugares como Sogamoso (Boyacá), en donde se intentó regular la actividad. ${ }^{23}$

En agosto de 2013, como consecuencia de todo lo que venía sucediendo alrededor de las discusiones sobre la prostitución y con la fuerte implicación de orden constitucional de la Sentencia T-629 de 2010, el senador Armando Benedetti presentó el Proyecto de Ley Ordinaria 079, cuyo objeto es:

Establecer medidas para garantizar la dignidad de las personas que ejercen la prostitución no forzada, a partir del reconocimiento de sus derechos como

20 Red de Trabajadoras Sexuales de Latinoamérica y el Caribe

21 En el caso de Bogotá, instituciones como la Secretaría Distrital de Integración Social (SDIS) adelantaron investigaciones y diálogos con población involucrada que se concentró en foros llamados "Hablemos sobre prostitución", en los que por primera vez se escucharon propuestas desde diversos sectores de las Organizaciones No Gubernamentales (ONG).

22 Bogotá ha sido la ciudad pionera en el tratamiento jurídico e institucional de la población que ejerce prostitución en el país, por medio del Acuerdo 400 de 2001, del Decreto 188 de 2002, del Decreto 469 de 2003 y del Acuerdo 079 de 2003, entre otros.

23 En Sogamoso se emitió el Acuerdo Municipal 005 de 2011. 
sujetos de especial protección constitucional, establecer acciones afirmativas en su favor, y delimitar conductas de los establecimientos comerciales dedicados a la prestación de servicios vinculados a esta actividad.

El Proyecto tuvo tres grandes objetivos: 1) reconocer la actividad como un trabajo y asegurar, como en cualquier otro y con todas las medidas de la seguridad social, a las personas que la desempeñen; 2) establecer obligaciones a los establecimientos y a las personas dedicadas a esta actividad, bajo la lógica de la protección de los derechos fundamentales emanados de la Sentencia T-629 de 2010; y 3) crear acciones afirmativas a favor de esta población, con el soporte interinstitucional que vincula varios ministerios como el de Educación, el de Salud y el del Interior, así como la Defensoría del Pueblo y el Instituto Colombiano de Bienestar Familiar, entre otros.

La justificación del Proyecto menciona la especial situación de vulnerabilidad de esta práctica y le concedió un estatus de actividad económica válida que, por las circunstancias socioeconómicas del país, se convierte en una alternativa sostenible, con la cual se pueden suplir las necesidades de las personas trabajadoras sexuales y de quienes están a su cargo.

Tanto en el Proyecto de Ley como en los antecedentes constitucionales queda claro que el Estado debe implementar acciones que conduzcan a controlar la actividad de la prostitución y a prevenir su expansión, por lo que se intenta evitar, de manera rotunda, la creación de incentivos para su crecimiento. Asimismo, la pretensión del Proyecto de Ley es que el Estado tome algunas medidas como las ya adoptadas para combatir la esclavitud sexual y la ESCNNA.

El Proyecto de Ley contiene un capítulo en el que se expresan los derechos y las garantías especiales de las personas que ejercen prostitución, como el derecho a recibir un trato diferencial por parte de la Administración, de acuerdo con su situación de vulnerabilidad.

El trato diferencial incluye medidas como el derecho a recibir información de las normativas, a formular políticas públicas para contrarrestar los efectos del ejercicio de la prostitución, a recibir oportunidades laborales y sociales alternativas y el derecho a desempeñar su actividad en condiciones dignas, saludables e higiénicosanitarias, entre otros.

En cuanto a los derechos laborales, en el Artículo 8 se instituye que existe presunción de contrato laboral, en coordinación con lo expresado por la Corte Constitucional. En el proyecto se postula que: 
Para todos los efectos legales, se presume que existe una relación laboral entre las personas que ejercen la prostitución y los establecimientos de comercio objeto de la presente ley, con las consecuencias contempladas en el Código Sustantivo del Trabajo, independientemente de la denominación contractual atribuida entre las partes.

Por otra parte, en el Capítulo II se definen las obligaciones para las personas que ejercen la prostitución, respecto al cuidado propio y de las personas que demanden los servicios, con especial énfasis en la salud; para ello, se hace obligatorio el uso del preservativo por cada relación, así como la asistencia periódica a los servicios de salud, con el fin de disminuir los riesgos asociados con este trabajo como las enfermedades de transmisión sexual (ETS).

De la misma forma como ordena una serie de derechos y obligaciones para quienes ejercen la prostitución, en el Capítulo V se plasman las disposiciones generales para los lugares que ofertan los servicios de las y los trabajadores sexuales.

En un primer momento, determina las obligaciones de los establecimientos. Se contempla el cumplimiento de todas las medidas legales para aquellos de tipo comercial, así como las correspondientes licencias de construcción, las normas referentes a intensidad auditiva, horario, ubicación y obtención de la matrícula mercantil, entre otras medidas de carácter general.

También se los obliga a cumplir unos lineamientos dirigidos a la protección de los derechos de las personas que ejercen la prostitución, como la promoción del uso del preservativo y de los medios de protección recomendados por las autoridades. Se exhorta a los propietarios, administradores y empleados a velar por un trato digno, por lo que se crea la obligación de asistir cada año a jornadas de información y educación en salud, derechos humanos y desarrollo personal, como se viene haciendo en la ciudad de Bogotá a partir de la emisión del Acuerdo 079 de 2003.

Si no se ejerce un adecuado control desde las instituciones o autoridades competentes, el Proyecto de Ley llama la atención sobre la especial atención en las conductas delictivas que se pueden promover y desarrollar dentro de los establecimientos como la trata de personas con fines de explotación sexual, la ESCNNA, la venta de alucinógenos, la esclavitud sexual y otras conductas sancionadas en el Código Penal colombiano. 
Según el Proyecto, las obligaciones de los establecimientos hacia sus trabajadores que ejercen la prostitución deben ceñirse a las disposiciones legales de un contrato laboral, por lo que en su Artículo 11 exige el cumplimiento de este tipo de contratos y la afiliación al sistema general de seguridad social.

Se propone la creación de un fondo denominado de Restablecimiento social de personas que ejercen prostitución, cuya finalidad, plasmada en el Artículo 21, es:

[...] prevenir, tratar y restablecer los derechos de las personas que ejercen la prostitución, creando programas especiales de atención a sus necesidades, campañas, estudios suscribiendo convenios, generando oportunidades, subsidios, y en general todas aquellas actividades que guarden una relación directa con el aspecto teleológico o finalista de la presente norma.

Dicho fondo sería sustentado por los aportes del presupuesto nacional, de las donaciones y los aportes voluntarios, de las multas a establecimientos de comercio y personas que ejerzan la prostitución e incumplan las disposiciones de la ley y de los rendimientos del propio fondo.

Por último, los Capítulos V y VI se refieren al importante rol de los medios masivos de comunicación y los centros educativos en la información a la población, para impedir el crecimiento de la actividad y del estímulo tanto a la promoción de la oferta como la demanda de la prostitución.

\section{Disposiciones para la aprobación del Proyecto de Ley}

Una vez el proyecto fue presentado por el senador Benedetti en el año 2013, se aunaron esfuerzos para iniciar el proceso legislativo en el Senado de la República. Las senadoras Gloria Inés Ramírez, Teresita García Romero y Astrid Sánchez se encargaron de presentar a discusión el Proyecto de Ley en la Comisión Séptima del Senado, que fue aprobado el 27 de noviembre del mismo año con las modificaciones realizadas por las senadoras nombradas, consistentes en seis recomendaciones generales: ${ }^{24}$

24 Para esta fase, el Proyecto de Ley fue discutido con organizaciones como la Corporación Opción, la Asociación Nacional de Mujeres Buscando Libertad, la organización Sueños Sin Límites, la Fundación Fénix y el Proyecto Fondo Mundial VIH; además, contó con la colaboración de las Secretarías de Integración Social y de la Mujer del Distrito Capital y del Ministerio de Salud y Protección Social. 
1. Se eliminaron los Artículos 15 y 16 del Proyecto de Ley inicial, que hacían referencia a la creación, por parte de los establecimientos, de una base de datos con el registro cronológico detallado de los servicios sexuales prestados. Además, fija a los establecimientos un tope de cobro de 30\% del precio, valor o de la contraprestación pactada por el servicio sexual cancelado o pendiente por cancelar a las personas que ejercen la prostitución. De acuerdo con las senadoras, estos Artículos "resultaban contrarios a los derechos a la intimidad, la privacidad, la honra y el buen nombre de quienes ejercen la prostitución, lo que resultaba claramente violatorio de los derechos fundamentales y contrario a la legislación". 25

2. Se incorporaron deberes para clientes o usuarios de servicios sexuales y para las autoridades, encaminados a eliminar los malos tratos, la marginación y otras formas de violencia presentes en este trabajo.

3. Las senadoras propusieron la elaboración de un nuevo capítulo que apunte a desestimular el ejercicio de la prostitución, por medio de alternativas laborales y de la posibilidad de vincular a las madres cabeza de familia y mujeres mayores de 45 años a las empresas.

4. La Ponencia incluyó un capítulo nuevo sobre educación, en el que se exhorta al diseño de estrategias de inclusión que permitan a las personas que ejercen prostitución la finalización de los ciclos de formación básica, media y secundaria. De igual forma, busca propiciar las condiciones que faciliten a esta población su acceso a la educación superior como estrategia para desestimular el ejercicio de la práctica.

5. En el plano preventivo se propuso que, por medio del Ministerio de Educación, se implementen y fortalezcan "programas pedagógicos de formación en derechos humanos, derechos sexuales y reproductivos, explotación sexual y cualquier forma de violencia de género". ${ }^{26}$

25 Gloria Inés Ramírez, "Aprobado en primer debate el proyecto de ley por el cual se reglamenta el ejercicio de la prostitución a nivel nacional", http://www.senado.gov.co/sala-de-prensa/opinion-de-senadores/item/18919aprobado-en-primer-debate-el-proyecto-que-reglamenta-el-ejercicio-de-la-prostitucion-a-nivel-nacional (acceso diciembre 3, 2013).

26 Ramírez, "Aprobado en primer debate el proyecto de ley por el cual se reglamenta el ejercicio de la prostitución a nivel nacional". 
6. Se agregó un capítulo en el que se insta a la formulación de una política pública de atención y apoyo integral a las personas que ejercen la prostitución, con el objetivo de garantizar sus derechos.

Sumado a estas recomendaciones, el Proyecto se sometió a consideraciones de algunas instituciones gubernamentales implicadas en la atención a la población objeto de la Ley. A continuación se enuncian las principales recomendaciones generales:

Tabla 1

Conceptos emitidos al Proyecto de Ley 079 de 2013

\begin{tabular}{|c|c|}
\hline Institución & Concepto \\
\hline \multirow{3}{*}{$\begin{array}{c}\text { Instituto } \\
\text { Colombiano } \\
\text { de Bienestar } \\
\text { Familiar } \\
\text { (ICBF) }\end{array}$} & $\begin{array}{l}\text { El proyecto carece de disposiciones que establezcan la prohibición de cualquier tipo de } \\
\text { explotación sexual comercial infantil, la cual se encuentra tipificada como delito en el } \\
\text { Código Penal. }\end{array}$ \\
\hline & $\begin{array}{l}\text { No se definen medidas de protección para hacer frente a esta problemática que afecta a la } \\
\text { niñez y la adolescencia en nuestro país. }\end{array}$ \\
\hline & $\begin{array}{l}\text { La iniciativa no contempla referencia alguna a la prohibición legal y constitucional existente } \\
\text { sobre la explotación sexual infantil como un delito sancionable por el ordenamiento jurídico. }\end{array}$ \\
\hline \multirow{6}{*}{$\begin{array}{l}\text { Defensoría del } \\
\quad \text { Pueblo }\end{array}$} & $\begin{array}{l}\text { Se debe tener en cuenta que los riesgos asociados con la prostitución callejera son mayores, } \\
\text { pues no es viable regularla debido a su carácter informal y es ahí en donde se prevé mayor } \\
\text { vulneración. }\end{array}$ \\
\hline & $\begin{array}{l}\text { Se considera necesario incluir los principios del respeto a la dignidad humana, solidaridad } \\
\text { y buena fe. }\end{array}$ \\
\hline & $\begin{array}{l}\text { En cuanto a las sanciones a los establecimientos por el incumplimiento de la ley, cabe señalar } \\
\text { que una suspensión o un cierre generaría efectos adversos para las personas que ejercen la } \\
\text { prostitución, ya que las dejaría sin un lugar de trabajo. }\end{array}$ \\
\hline & $\begin{array}{l}\text { El Artículo } 23 \text { propone en su parágrafo } 2 \text { que, en el marco de la responsabilidad social } \\
\text { empresarial, se incentive la contratación de personas que hayan estado en ejercicio de la } \\
\text { prostitución; sin embargo, las personas tendrían que informar su actividad previa, lo que } \\
\text { vulnera su derecho a la intimidad. }\end{array}$ \\
\hline & $\begin{array}{l}\text { Es necesario crear un programa de incentivos para acceder a la educación superior en } \\
\text { universidades acreditadas. }\end{array}$ \\
\hline & $\begin{array}{l}\text { El DANE, en coordinación con el Ministerio de Salud, de Protección Social y de Trabajo, } \\
\text { debe hacer un estudio de caracterización de la población previo a la emisión de la ley. }\end{array}$ \\
\hline
\end{tabular}




\begin{tabular}{|c|c|}
\hline \multirow{3}{*}{$\begin{array}{l}\text { Ministerio } \\
\text { de Defensa }\end{array}$} & $\begin{array}{l}\text { En relación con el Artículo } 8 \text { del Proyecto, referente a la presunción de contrato laboral } \\
\text { entre las personas que ejercen la prostitución, se considera que esta disposición debe ser } \\
\text { analizada por el Ministerio de Trabajo, por cuanto desborda la protección general establecida } \\
\text { en el ordenamiento laboral. }\end{array}$ \\
\hline & $\begin{array}{l}\text { Entre las obligaciones para los establecimientos donde se ejerza la prostitución, se sugiere } \\
\text { incluir la fijación de avisos que indiquen los números o las líneas de atención del Comité } \\
\text { interinstitucional de lucha contra la trata de personas; sin ellos, dichos lugares se harían } \\
\text { acreedores a sanciones pecuniarias y, en caso de reincidencia en el incumplimiento, se } \\
\text { facultaría el cierre del lugar. }\end{array}$ \\
\hline & $\begin{array}{l}\text { Respecto a la forma del contrato laboral, no sería procedente limitar las modalidades de } \\
\text { contratación, por cuanto, como se desprende del mismo proyecto, las mujeres y los hombres } \\
\text { que ejercen la prostitución lo hacen con diferentes variables y formas. }\end{array}$ \\
\hline \multirow{3}{*}{$\begin{array}{l}\text { Ministerio } \\
\text { de Educación }\end{array}$} & $\begin{array}{l}\text { El Proyecto busca facilitar el ingreso de las personas que ejercen la prostitución a programas } \\
\text { académicos de educación superior; sin embargo, la citada disposición podría vulnerar la } \\
\text { autonomía de tales instituciones, reconocida por el Artículo } 69 \text { de la Constitución Política. }\end{array}$ \\
\hline & $\begin{array}{l}\text { El Proyecto busca instituir medidas especiales para financiar los estudios de educación su- } \\
\text { perior que adelanten las personas que ejercen la prostitución; no obstante, el Ministerio de } \\
\text { Educación considera que esta propuesta puede no estar acorde con la política de fomento } \\
\text { de la educación superior. }\end{array}$ \\
\hline & $\begin{array}{l}\text { El Proyecto insta a que el Ministerio de Educación implemente campañas educativas destinadas } \\
\text { a la prevención de cualquier forma de explotación sexual y violencia de género; empero, el } \\
\text { Ministerio no comparte que se haga referencia a "campañas educativas", pues se ha considerado } \\
\text { que los distintos agentes educativos no deben encargarse de este tipo de actividades y que } \\
\text { deberían ser responsabilidad de otros sectores como cultura y comunicaciones, como parte } \\
\text { de la articulación que deben tener con el sector. }\end{array}$ \\
\hline \multirow[t]{2}{*}{$\begin{array}{l}\text { Ministerio del } \\
\text { Trabajo }\end{array}$} & $\begin{array}{l}\text { Acerca de la redacción del numeral } 1 \text {, es preciso incluir que los derechos sexuales y reproductivos } \\
\text { de las personas que ejercen la prostitución tienen espacial relevancia y recalcar la posibilidad } \\
\text { que tienen hombres y mujeres para tomar decisiones autónomas — sin coacción, violencia o } \\
\text { discriminación— sobre su propio cuerpo, en el ámbito de la sexualidad y la reproducción. }\end{array}$ \\
\hline & $\begin{array}{l}\text { Es pertinente sumar un capítulo completo e independiente que regule las situaciones } \\
\text { relacionadas con el acceso y la atención a los riesgos laborales. }\end{array}$ \\
\hline
\end{tabular}

Fuente: elaboración propia con base en documentos internos del Comité Interinstitucional sobre trata de personas.

Cada una de las instituciones dio un concepto favorable al Proyecto de Ley, con base en los criterios constitucionales y las directrices expuestas por la Corte Constitucional.

Desde 2014, el programa de prostitución en Bogotá ha sido manejado por la Secretaría de la Mujer; esto generó debate no solo en la Secretaría Distrital de Integración Social (SDIS), que había estado por años a su cargo, pues se visibilizó que en esta 
dinámica social no solo se encuentran mujeres en situación de prostitución sino también hombres ofertantes sexuales. Debido a ello, se integraron poblaciones como la LGBTI, que son vulnerados en esta actividad comercial. El manejo de temas asociados con la explotación sexual sí quedó bajo la responsabilidad de la SDIS, apoyada por la Fundación Renacer. ${ }^{27}$

De acuerdo con Edward Hernández, funcionario de la Secretaría Distrital de la Mujer, esta institución:

[...] a la fecha no ha adelantado estudios en relación con la salud ocupacional y los riesgos laborales derivados del ejercicio de la prostitución; no obstante, en curso de la asesoría psicosocial, jurídica e intervención social que las profesionales realizan con mujeres en ejercicio de la prostitución, se han observado las siguientes afectaciones para la salud que pueden estar relacionadas con la actividad realizada y que la literatura científica en ocasiones reporta también relacionada.

Tabla 2

Afectaciones a la salud de personas en ejercicio de prostitución

\begin{tabular}{|c|l|}
\hline $\begin{array}{c}\text { Aspecto relacionado con el } \\
\text { ejercicio de la prostitución }\end{array}$ & \multicolumn{1}{|c|}{ Afectación a la salud } \\
\hline & $\begin{array}{l}\text { Mayor resequedad cutánea } \\
\text { Obesidad } \\
\text { Alteraciones hormonales } \\
\text { Afectaciones visuales } \\
\text { Alteraciones del estado de ánimo } \\
\text { Aumento de ansiedad } \\
\text { Alteraciones de memoria } \\
\text { Dificultades con la atención y la concentración }\end{array}$ \\
\hline \multirow{5}{*}{ Exposición a la luz } & $\begin{array}{l}\text { Alteraciones hormonales } \\
\text { Alteraciones del ritmo circadiano } \\
\text { Afecciones cutáneas }\end{array}$ \\
\hline Exposición al ruido & $\begin{array}{l}\text { Deterioro auditivo } \\
\text { Aumento de riesgo cardiovascular } \\
\text { Alteraciones digestivas } \\
\text { Alteraciones hormonales } \\
\text { Dificultades con la atención y la concentración } \\
\text { Mayor agresividad }\end{array}$ \\
\hline Consumo de sustancias & $\begin{array}{l}\text { Mayores tasas de adicción a sustancias como el cigarrillo, el alcohol } \\
\text { yotras drogas } \\
\text { Pérdida de habilidades cognitivas } \\
\text { Alteraciones del estado de ánimo, con mayor prevalencia de } \\
\text { depresión y ansiedad }\end{array}$ \\
\hline
\end{tabular}

27 EL objetivo de la Fundación Renacer es ofrecer atención integral a niños, niñas y adolescentes víctimas de explotación sexual. 


\begin{tabular}{|c|c|}
\hline Actividad sexual & $\begin{array}{l}\text { Mayor probabilidad de ETS } \\
\text { Mayor probabilidad de cáncer de cuello uterino } \\
\text { Estreñimiento } \\
\text { Afecciones de garganta } \\
\text { Alteración de estados emocionales }\end{array}$ \\
\hline Doble vida & $\begin{array}{l}\text { Alteraciones cognitivas } \\
\text { Mitomanía } \\
\text { Trastornos de personalidad }\end{array}$ \\
\hline $\begin{array}{c}\text { Contexto en el que se ejerce la } \\
\text { prostitución }\end{array}$ & $\begin{array}{l}\text { Mayor probabilidad de muerte violenta } \\
\text { Baja tolerancia a la frustración } \\
\text { Mayor exposición a maltrato físico, verbal y psicológico }\end{array}$ \\
\hline Estigma sobre la prostitución & $\begin{array}{l}\text { Mayor ideación suicida } \\
\text { Mayor índice de depresión y ansiedad } \\
\text { Baja autoestima } \\
\text { Baja autoeficacia }\end{array}$ \\
\hline
\end{tabular}

Fuente: Edwin Hernández, Afectaciones a la salud de personas en ejercicio de prostitución (Bogotá: Secretaría de la Mujer, 2014).

Si bien a partir del reconocimiento jurisprudencial de la prostitución como cualquier otro trabajo hubo garantía de acceso al sistema de seguridad social integral (salud, pensiones, riesgos laborales, caja de compensación familiar), para las personas mayores de edad que se encuentran ejerciendo esta actividad aún no es una realidad, pese a que se ajusta a los presupuestos de validez de todo contrato del Código Civil (persona legalmente capaz, libre de vicios de consentimiento, objeto y causa lícitos) y del Código Sustantivo del Trabajo en lo que respecta a la aplicación de las disposiciones legales en materia de seguridad social. En este caso, operarían como trabajadores independientes o, en su defecto, si media una vinculación laboral, tendrían derecho a todos los postulados laborales y de seguridad social como la estabilidad laboral reforzada (en caso de embarazo), indemnización por despido sin justa causa, prestaciones sociales, vacaciones, primas y cotización a seguridad social (EPS, ARL y ARP).

El anterior enunciado tiene vacíos jurídicos, no solo ante la reglamentación de los Códigos Civil y Sustantivo del Trabajo, sino frente al Código Penal, tanto en la oferta como en la demanda de servicios sexuales, ya que la promoción, oferta y captación de personas para el comercio sexual consensuado podría tener visos de inducción a la prostitución, al proxenetismo, al constreñimiento, a la posible explotación sexual y por qué no, a la trata de personas con fines de explotación sexual.

Por tanto, mientras no haya seguridad jurídica, más allá de la obligación que tendrían en el aporte al régimen contributivo, los empresarios del sexo no entrarían a aplicar estos parámetros legales; así, las personas que se mueven en torno a la oferta del sexo pago quedan en la misma condición de vulnerabilidad y es el Estado el que, 
la mayoría de las veces por medio del régimen subsidiado, se encarga de ofrecerles unos mínimos frente al Sistema General de Seguridad Social en Salud (SGSSS), pese al usufructo económico de los dueños de establecimientos del sexo de un tercero.

Para el caso de toda persona menor de 18 años involucrada en el comercio sexual es importante recalcar que este no cabe dentro del aspecto laboral, ya que se considera explotación sexual comercial con niños, niñas y adolescentes y está penalizado; por ello, el objeto contractual sería ilícito, pero ¿qué pasa cuando los demandantes de servicios sexuales son menores de edad que pagan por tener sexo con una persona mayor de edad? ¿Qué sucede cuando son menores de edad que pagan por tener sexo con otros menores de edad? ¿Y en el caso de que sus padres o grupo parental sean los encargados de iniciarlos sexualmente con una mujer en situación de prostitución?

Aunque lo anterior nutre la complejidad de la prostitución y lo que implica la reglamentación del trabajo sexual para el mundo adulto en la oferta de servicios sexuales o eróticos pagos, se aviva el debate que suscita la actividad del ejercicio sexual en cuanto a la interpretación y aplicación de los postulados jurídicos, porque se debe revisar la correspondencia entre lo que constituye el derecho al trabajo y al acceso a las garantías en un Estado social de Derecho, cimentado en los principios y derechos fundamentales mediante sus instituciones, la norma ${ }^{28}$ (Código Sustantivo del Trabajo, Código Civil, Código Penal y Código de Policía, entre otros) y la jurisprudencia.

\section{Conclusiones}

El panorama parece alentador en términos del reconocimiento de los derechos de las personas que ejercen la prostitución, mas el recorrido para la promulgación final de una ley requiere disposición política, que tiene una considerable relación con la visión y la perspectiva moral de la sociedad.

La promulgación o el rechazo de la Ley 079 de 2013 evaluará la tendencia a aceptar y a defender los derechos de una población históricamente discriminada, labor que estará a cargo del Congreso de la República como institución que representa los ideales, los intereses y las necesidades de todos los ciudadanos en el marco de un Estado social de Derecho.

28 A manera de conclusión, se anexa cuadro comparativo entre la relación laboral y la relación civil. 
El debate legislativo sobre la prostitución no es limitado. Al observar el contexto nacional e internacional, es notorio el dinamismo que toma la prostitución en las diversas agendas legislativas: en algunos países, más avanzado; en otros, rezagado. Por ejemplo, en Brasil se adelanta la discusión del Proyecto de Ley 4.211/ 2012, presentado por el diputado Jean Wyllys, que busca que los profesionales del sexo sean tratados con igualdad y con los mismos derechos de los que goza el resto de trabajos.

Desde otro ámbito, México intenta combatir la trata de personas con fines de explotación sexual ${ }^{29}$ mediante una ley; además, en la actualidad cursa una iniciativa liderada por la senadora Mónica Arriola para reglamentar la prostitución desarrollada sin que medie ninguna coacción ni se usufructúe un tercero.

En otras latitudes, países como Holanda y Alemania representan los modelos prolegalización de la prostitución, mientras Suecia ha implementado un modelo considerado neoabolicionista, en el que se castiga al cliente que solicita servicios sexuales.

Lo cierto es que existen tantos informes y estudios como cifras diversas que justifican o critican determinado modelo jurídico. Empero, es necesario reconocer que no se puede instituir un paradigma jurídico global, pues si algo se ha logrado avanzar en el estudio de la prostitución es su polimórfica constitución, que depende de dimensiones como el género, la raza y la clase social.

Sumado a estos factores, las estructuras de los países en ámbitos políticos, económicos y sociales crean cierta propensión hacia las dinámicas del comercio sexual, por lo que, en el caso de las redes de trata de personas, es posible distinguir países expulsores y otros de recepción.

De acuerdo con múltiples informes, ${ }^{30}$ Colombia se ha constituido como un país expulsor, lo que permite comprender una realidad en la que el comercio sexual tiene una magnitud considerable que debe ser afrontada con mayor rigurosidad,

29 A partir del 14 de marzo entró en vigor la Ley para la protección, atención y asistencia a las víctimas de los delitos en materia de trata de personas, en México D. F.

30 Fernanda Ezeta, La trata de personas: aspectos básicos (México D. F: Organización Internacional para las Migraciones, Comisión Interamericana de Mujeres, Instituto Nacional de Migración, Instituto Nacional de las Mujeres, 2006), 69; UNODC, The Globalization of Crime. A Transnational Organized Crime Threat Assessment (Viena: Publicaciones Naciones Unidas, 2010), 303; Unicef, Aprovecharse del abuso: una investigación sobre la explotación sexual de nuestros niños y niñas (Nueva York: Unicef, 2012), 39. 
seriedad y compromiso tanto por las instituciones del Estado como por la sociedad en general.

El actual desarrollo jurídico parece favorecer las condiciones de una población que ha sido desprotegida y, por eso, la Sentencia T-629 de 2010 se convierte en el suelo constitucional. Asimismo, es necesario dar cumplimiento efectivo a lo enunciado en la referida sentencia, mediante la formulación de una ley que permita garantizar los derechos fundamentales de este segmento y reforzar la materia laboral y de acceso real al SGSSS.

\section{Referencias}

Alcaldía Mayor de Bogotá. Acuerdo 79 de 2003, "Por el cual se expide el Código de Policía de Bogotá D. C.". Bogotá: Registro Distrital 2799, 20 de enero de 2003.

Anderson, Benedict. Comunidades imaginadas: reflexiones sobre el origen y la difusión del nacionalismo. México D. F: Fondo de Cultura Económica, 1993.

Appiah, Kwame. La ética de la identidad. Buenos Aires: Latingráfica, 2007.

Bourdieu, Pierre. Sociología y cultura. México D. F: Grijalbo, 1984.

Colombia, Congreso de la República. Ley 100 de 1993, "Por la cual se crea el sistema de seguridad social integral y se dictan otras disposiciones". Bogotá: Diario Oficial No. 41.148, 23 de diciembre de 1993.

Colombia, Congreso de la República. Ley 57 de 1887, "Código Civil". Bogotá: Imprenta de Gaitán, 1873.

Colombia, Congreso de la República. Ley 599 de 2000, "Por la cual se expide el Código Penal". Bogotá: Diario Oficial No. 44.097, 24 de julio de 2000.

Colombia, Congreso de la República. Ley 906 de 2004, "Por la cual se expide el Código de Procedimiento Penal (Corregida de conformidad con el Decreto 2770 de 2004)". Bogotá: Diario Oficial No. 45.658, 1 de septiembre de 2004.

Colombia, Corte Constitucional. Sentencia C-636 de 16 de septiembre de 2009. M. P. Mauricio González Cuervo.

Colombia, Corte Constitucional. Sentencia T-620 de 14 de diciembre de 1995. M. P. Vladimiro Naranjo Mesa.

Colombia, Corte Constitucional. Sentencia T-629 de 13 de agosto de 2010. M. P. Juan Carlos Henao Pérez.

Colombia, Presidencia de la República. Decreto 1355 de 1970, "Por el cual se dictan normas sobre Policía”. Bogotá: Diario Oficial No. 33.139, 4 de septiembre de 1970.

Colombia, Presidencia de la República. Decreto 3743 de 1950, "Por el cual se modifica el Decreto No. 2663 de 1950, sobre Código Sustantivo del Trabajo". Bogotá: Diario Oficial No. 27.504, 11 de enero de 1951. 
Comité Interinstitucional sobre Trata de Personas. Conceptos emitidos al Proyecto de Ley 079 de 2013. Bogotá: mimeo, 2013.

Ezeta, Fernanda. La trata de personas: aspectos básicos. México D. F: Organización Internacional para las Migraciones, Comisión Interamericana de Mujeres, Instituto Nacional de Migración, Instituto Nacional de las Mujeres, 2006.

Hernández, Edwin. Afectaciones a la salud de personas en ejercicio de prostitución. Bogotá: Secretaría de la Mujer, 2014.

Laverde, Carlos Alfonso. "Aportaciones desde una perspectiva socio-jurídica al debate del trabajo sexual femenino en Colombia”. Logos Ciencia \& Tecnología 6, núm. 1 (junio 2014): 56-69.

Laverde, Carlos Alfonso. "Impacto dela normatividad jurídica del trabajo sexual en la ciudad de Bogotá sobre las condiciones laborales y socialesde las mujeres trabajadoras sexuales". Tesis de Maestría en Estudios Políticos y Sociales, Universidad Nacional Autónoma de México (UNAM), 2014.

Laverde, Carlos Alfonso. "Mercado del sexo: reflexiones desde la economía al comercio sexual". Via Inveniendi et Iudicandi 8, núm. 1 (2013), http://revistas.usantotomas.edu. co/index.php/viei/article/view/847/1128 (acceso febrero 21, 2014).

Obregón, Diana. "Médicos, prostitución y enfermedades venéreas en Colombia (18861951)". História, Ciências, Saúde-Manguinhos 9, supl. (2002): 161-186, www.scielo. br/pdf/hcsm/v9s0/07.pdf (acceso noviembre 24, 2013).

Ramírez, Gloria Inés. "Aprobado en primer debate el proyecto de ley por el cual se reglamenta el ejercicio de la prostitución a nivel nacional". http://www.senado.gov. co/sala-de-prensa/opinion-de-senadores/item/18919-aprobado-en-primer-debateel-proyecto-que-reglamenta-el-ejercicio-de-la-prostitucion-a-nivel-nacional (acceso diciembre 12, 2013).

República de Colombia. Constitución Política. Bogotá: Legis, 2002.

Sen, Amartya. Desarrollo y libertad. Barcelona: Planeta, 2000.

Tirado, Misael. "El biopoder como estrategia política del cuerpo: comercio y explotación sexual" en Debates en Filosofía y Ciencia Política, compilado por Claudina Orunesu y Pablo Slavin, 423-434. Mar del Plata: Universidad de Mar del Plata, 2012.

Tirado, Misael. "El debate entre prostitución y trabajo sexual: una mirada desde lo sociojurídico y la política pública". Revista de Relaciones Internacionales, Estrategia y Seguridad 6, núm. 1 (2011): 127-148.

Tirado, Misael. "Implicações do Trabalho Sexual como atividade legalmente reconhecida: Uma cercamento ao trabalho sexual desde suas dimensões sociológicas e económicas”. Revista Prolegómenos: Derechos y Valores XIV, núm. 27 (2011): 247-265.

Tirado, Misael. Comercio sexual. Bogotá: Instituto Latinoamericano de Altos Estudios, 2013.

Tirado, Misael. Comercio sexual: una mirada desde la sociología jurídica. Lima: Instituto Internacional de Derecho y Sociedad, 2010. 
Unicef. Aprovecharse del abuso: una investigación sobre la explotación sexual de nuestros niños y niñas. Nueva York: Unicef, 2012.

UNODC. The Globalization of Crime. A Transnational Organized Crime Threat Assessment. Viena: Publicaciones Naciones Unidas, 2010. 


\section{Anexo}

Mediante Sentencia T-629 de 2010, la Corte Constitucional decidió tutelar derechos fundamentales de una trabajadora sexual en estado de embarazo. Este caso permitió plantear una serie de preguntas y problemas que se relaciona con la concepción de la actividad de la prostitución y la manera como es relacionan por la normatividad. A continuación se presentan situaciones hipotéticas que pretenden establecer las dificultades del conflicto jurídico frente a un hecho social como el del trabajo sexual en el campo del Derecho Laboral y del Derecho Civil.

Previamente se presenta un cuadro comparativo:

Tabla 3

Relación laboral frente a relación civil

\begin{tabular}{|c|c|c|}
\hline & Relación laboral & Relación civil \\
\hline Características & $\begin{array}{l}\text { - Prestación personal de un servicio de una } \\
\text { persona natural a una persona natural o } \\
\text { jurídica } \\
\text { - Remuneración } \\
\text { - Subordinación (dependencia) }\end{array}$ & $\begin{array}{l}\text { - Prestación personal de un servicio de } \\
\text { una persona natural a una persona } \\
\text { natural o jurídica } \\
\text { - Remuneración }\end{array}$ \\
\hline Tipo de contrato & - Laboral & - Civil de prestación de servicios \\
\hline Marco normativo & - Código Sustantivo del Trabajo & - Código Civil \\
\hline Seguridad social & $\begin{array}{l}\text { - Es asumida tanto por el empleador como } \\
\text { por el trabajador en la proporción de la ley }\end{array}$ & - Es asumida por el contratista \\
\hline
\end{tabular}

Si bien en Colombia la prostitución es una actividad lícita para mayores de edad que decidan libremente la prestación del servicio, el Código Penal señala como delito:

Artículo 213. Inducción a la prostitución. El que con ánimo de lucrarse o para satisfacer los deseos de otro, induzca al comercio carnal o a la prostitución a otra persona, incurrirá en prisión de dos (2) a cuatro (4) años y multa de cincuenta (50) a quinientos (500) salarios mínimos legales mensuales vigentes. ${ }^{31}$

A partir del marco suministrado resuelva los siguientes casos. Determine el tipo de relación (laboral o civil, las obligaciones sobre los aportes a seguridad social, riesgos laborales y las implicaciones penales) en cada uno de ellos:

31 Al respecto, puede verse Colombia, Corte Constitucional, Sentencia C-636 de 16 de septiembre de 2009, M. P. Mauricio González Cuervo. 
1. L es trabajadora sexual y presta sus servicios en una casa de lenocinio en el centro de la ciudad. Debe permanecer en el lugar entre las 6:00 p. m. y las 03:00 a. m. Su trabajo es atender a todos los clientes que así lo deseen. El servicio se presta en el lugar. El propietario del lugar, X, le paga una remuneración básica y unas comisiones sobre el valor que paga cada cliente por cada prestación.

2. J es estudiante universitario. Ha conocido una página electrónica que es propiedad y es administrada por Pedro. La página ofrece servicios sexuales de jóvenes estudiantes dirigida a clientes con el perfil de hombres ejecutivos. Aparece un número de teléfono celular que contesta Pedro. Los potenciales clientes observan las fotografías de varios jóvenes —entre ellos, J- que prestan los servicios y llaman a Pedro, quien concreta el valor del servicio. El encuentro puede llevarse a cabo en la casa del usuario o en un hotel. El cliente le entrega el dinero a J y este debe llevarlo a Pedro para que le entregue lo que le corresponde.

3. W es transexual. Ella ha creado su propia página electrónica, en la que ofrece sus servicios. Estos son prestados en su apartamento o en hoteles de su confianza. Los clientes llaman al teléfono celular que allí aparece y concretan con W el valor y el tipo de servicio que requieren. Le pagan a $\mathrm{W}$ sin intermediarios. 